University of Nebraska - Lincoln

DigitalCommons@University of Nebraska - Lincoln

June 2001

\title{
Child Sexual Abuse in Asian American Families: An Examination of Cultural Factors That Influence Prevalence, Identification, and Treatment
}

\author{
Kristine T. Futa \\ Permanente Medical Group, Union City, CA \\ Eugenia Hsu \\ University of Nebraska-Lincoln \\ David J. Hansen \\ Univertsity of Nebraska-Lincoln, dhansen1@unl.edu
}

Follow this and additional works at: https://digitalcommons.unl.edu/psychfacpub

Part of the Psychiatry and Psychology Commons

Futa, Kristine T.; Hsu, Eugenia; and Hansen, David J., "Child Sexual Abuse in Asian American Families: An Examination of Cultural Factors That Influence Prevalence, Identification, and Treatment" (2001). Faculty Publications, Department of Psychology. 101.

https://digitalcommons.unl.edu/psychfacpub/101

This Article is brought to you for free and open access by the Psychology, Department of at DigitalCommons@University of Nebraska - Lincoln. It has been accepted for inclusion in Faculty Publications, Department of Psychology by an authorized administrator of DigitalCommons@University of Nebraska - Lincoln. 


\title{
Child Sexual Abuse in Asian American Families: An Examination of Cultural Factors That Influence Prevalence, Identification, and Treatment
}

\author{
Kristine Toshiko Futa, Eugenia Hsu, and David J. Hansen \\ University of Nebraska-Lincoln
}

Submitted August 2000; revised September 2000; accepted October 2000.

\begin{abstract}
Child sexual abuse affects thousands of families each year. Issues pertaining to the prevalence, identification, and treatment of sexual abuse have been relatively well explored in the literature as they pertain to the dominant European American culture. These issues, however, are still relatively unexplored in terms of how sexual abuse affects Asian American families and the Asian American community. We review the relevant literature in Asian American families. These matters are explored in the context of Asian American values such as collectivity, conformity, inconspicuousness, middle position virtue, shame, self-control, and fatalism. Attitudes toward family, sexuality, and the mental health system are also discussed. Cultural and institutional barriers to underutilizing mental health services are also explored, and suggestions for overcoming these barriers are offered.
\end{abstract}

Key words: child sexual abuse, Asian Americans, cultural factors, treatment barriers.

The problem of child sexual abuse has continually received increased attention in American society in recent decades. This is undoubtedly due, at least in part, to our increasing awareness of the prevalence and impact of sexual abuse. In the Third National Incidence Study of Child Abuse and Neglect (NIS-3), the most comprehensive study of the incidence of child abuse and neglect to date, it was estimated in 1993 that approximately 217,700 children nationwide were known to have experienced harm from sexual abuse (National Center on Child Abuse and Neglect, 1996). Because many incidences of abuse are not identified or reported, the actual incidence of abuse is probably significantly larger than this estimated figure (Beutler, Williams, \& Zetzer, 1994; Faller, 1993).

The short-term correlates of childhood sexual abuse in the European American community have been relatively well explored (cf. Browne \& Finkelhor, 1986a, 1986b; Faller, 1993; Finkelhor \& Browne, 1985; Hanson, 1990; Mrazek \& Mrazek, 1981; Wolfe \& Wolfe, 1988). The possible psychological consequences of sexual abuse are numerous and variable. However, no symptom or syndrome is found universally in all victims. Many variables may affect whether and how abuse has an impact on the victim, including factors such as the gender of the victim and perpetrator, the victim's relationship to the perpetrator, the type and severity of abuse, the duration of and time since the abuse, and family reaction following disclosure (Browne \& Finkelhor, 1986a; Faller, 1993; Hecht \& Hansen, in press; Ryan, 1997). Some victims may not be substantially impacted by abuse due to protective factors that prevent or reduce the negative effects of maltreatment (e.g., good family and social support, positive school experiences, therapy) (Beutler et al., 1994; Cicchetti \& Toth, 2000; Falshaw, Browne, \& Hollin, 1996; Hecht \& Hansen, 1999, in press).

Sexual abuse may be associated with a number of internalizing behaviors, including anxiety (e.g., McClellan, Adams, Douglas, McCurry, \& Storck, 1995; Ryan, 1997), depression (e.g., Livingston, 1987; Ryan, 1997; Wozencraft, Wagner, \& Pelligrin, 1991), problems with self-esteem (e.g., Tong, Oates, \& McDowell, 1987), suicidal ideation and attempts (e.g., Bayatpour, Wells, \& Holford, 1992; Bensley, Van Eenwyk, Spieker, \& Schoder, 1999; 
McClellan et al., 1995; Ryan, 1997; Wozencraft et al., 1991), sleep disturbances (e.g., McClellan et al., 1995; Wells, McCann, Adams, Voris, \& Ensign, 1995), somatic complaints (e.g., Livingston, 1987), and fear of males (e.g., Wells et al., 1995). Externalizing behavior problems may also be present, including self-abusive behaviors (e.g., McClellan et al., 1995), delinquency (e.g., Einbender \&Friedrich, 1989), and cruelty to animals and other people (e.g., Einbender \& Friedrich, 1989; McClellan et al., 1995). In addition, problems with school performance (e.g., Einbender \& Friedrich, 1989; Wells et al., 1995), as well as problems with relationships and social competence (e.g., Einbender \& Friedrich, 1989; Ryan, 1997), have been identified as correlates of child sexual abuse. Adolescent victims of sexual abuse may also exhibit substance abuse problems (Harrison, Hoffman, \& Edwall, 1989; McClellan et al., 1995; Ryan, 1997; Singer, Song, \& Ochberg, 1994). Sexually abused children are likely to know more about sex and are more interested and curious about sexual matters or genital regions (e.g., Friedrich \& Reams, 1987; Wells et al., 1995) and they may be more self-conscious about their own body (Wells et al., 1995) than children who have not been sexually abused. Heightened sexual activity, such as compulsive masturbation, precocious sexual play, and overt sexual acting out toward adults and peers have also been found among abused youth (e.g., McClellan et al., 1995).

Currently, research focusing on sexual abuse in minority populations is minimal. Literature on sexual abuse in Asian American populations is particularly sparse. An understanding of culturally specific abuse-related issues in Asian American populations is important in providing culturally sensitive assessment and treatment services to this population. Therefore, the purpose of this article is to summarize the existing literature pertaining to child sexual abuse victims in Asian American populations. Culturally specific issues will be explored in terms of their possible influence on the prevalence, identification, and reporting of child sexual abuse to help provide a better understanding of what is known in this area. Information and recommendations from the literature on working with Asian American clients in general, as well as literature specifically on child sexual abuse treatment, are reviewed in an effort to identify issues relevant for treating child sexual abuse in Asian American families. Although a thorough discussion of culturally relevant intervention and prevention with sexual abuse perpetra- tors is also important, it is beyond the scope of this article, which focuses on victims of childhood sexual abuse.

\section{ASIAN AMERICAN FAMILIES AND CHILD SEXUAL ABUSE}

\section{The Diversity of Asian Americans}

Asian Americans are a diverse population. For example, the terms "Asian American" and "Asian/Pacific Islander American" apply to members of 25 groups (Uba, 1994) and as many as 40 distinct cultural subgroups (Sandhu, 1997). According to Uba (1994), the groups were classified under these terms due to similar appearance, similar cultural values, and a common ethnic origin in Asia and the Pacific Islands. In addition to differences in country of origin, Asian Americans as individuals differ in terms of their generation in America (e.g., immigrant, first generation, second generation), level of bilingualism, and level of adherence to traditional customs (Chan, 1992). Lee (1996) also notes the following differences among Asian American groups: primary spoken language, ability to speak English, educational attainment, family income, assimilation, acculturation, religious beliefs, and exposure to war trauma.

The Asian American groups primarily studied by psychologists include persons of Cambodian, Chinese, Filipino, Hmong, Japanese, Korean, Lao, Mien, and Vietnamese ancestry (Uba, 1994). We note specifics regarding ethnic origin when information is available and pertinent. We focus on Asians in America and exclude research conducted on Asians abroad. In general, we use the term Asian American to refer to both immigrant and American-born Asians, which is consistent with other researchers in this area (Zane \& Sue, 1991).

\section{Incidence of Abuse}

Little research is available on the prevalence of sexual abuse in the Asian American population. The available research, however, suggests an overall low rate of reported abuse (e.g., sexual abuse, physical abuse, emotional maltreatment, neglect) in Asian American communities. For example, in 1997, 40 states provided data on the racial or ethnic backgrounds of abuse victims reported to state child-protective service agencies (National Center on Child Abuse and Neglect, 1999). Approximately two thirds of the 585,512 reported abuse victims were European American (66.7\%), approximately one third of the victims were African American (29.5\%), and 2.5\% were 
American Indian/Alaska Native. The percentage for Hispanic Americans obtained from only 35 states was $13.3 \%$. Only $1.3 \%$ of the 585,512 reported abuse victims were Asian American (National Center on Child Abuse and Neglect, 1999). These figures may be compared to the ethnic composition of the same 40 states in the United States to provide a clearer picture of the rate of reported abuse. The distribution of ethnic groups were approximately 78.9\% European American; 15.4\% African American; 4.5\% Asian or Pacific Islander; and 1.2\% American Indian/Alaska Native. In addition, the ethnic composition of the 35 states that identified Hispanic American was $18.8 \%$ (National Center on Child Abuse and Neglect, 1999). When comparing figures of reported abuse to those of the population residing in these states, it is apparent that African Americans and American Indian/Alaska Native communities are overrepresented in terms of reported abuse, while European American, Hispanic American, and Asian American communities are underrepresented in terms of reported abuse.

Similarly, the literature suggests a low rate of reported sexual abuse in the Asian American community. However, no known formal studies directly assess the incidence of sexual abuse in Asian American populations. Rao, DiClemente, and Ponton (1992) reviewed 2007 charts at the Child and Adolescent Sexual Abuse Resource Center in San Francisco, California. The researchers found the racial/ ethnic distribution of 2007 child sexual abuse cases. The rates of sexual abuse cases were 37.6\% African American, 25.9\% European American, 21.9\% Hispanic American, $6.6 \%$ Asian, $6.7 \%$ racially mixed, and $0.5 \%$ other races. Again, these figures may be compared to the general census of San Francisco for a better comparative understanding of reported abuse among the ethnic groups. In 1990, the ethnic distribution of the San Francisco community was approximately 54\% European American; 29\% Asian American; 14\% Hispanic American; 11\% African American; and $1 \%$ American Indian, Eskimo, or Aleut (U.S. Bureau of the Census, 1994). Again, European Americans and Asian Americans were underrepresented in reported sexual abuse, whereas African Americans were overrepresented in terms of rates of reported sexual abuse. However, based on these comparisons, Hispanic Americans were also overrepresented in this community. It is apparent that Asian American victims were the least likely to appear at this sexual abuse resource center. This low rate of reported sexual abuse is consistent with the clinical impression of professionals who concentrate on sexual abuse cases within the Asian American community (Thomas, 1992; Yap, 1986).

In another study, Ima and Hohm (1991) reviewed 158 clinical files of child maltreatment cases (i.e., physical abuse, sexual abuse, emotional abuse, neglect) referred to the Union of Pan Asian Communities (UPAC). All cases were of Asian and Pacific Islander refugees and immigrants (i.e., Cambodian, Hmong, Korean, Laotian, Filipino, Samoan, and Vietnamese) in the San Diego, California, area. There were no Chinese or Japanese cases in the UPAC program. These particular child maltreatment cases were referred to UPAC by Child Protective Services due to the language barriers and culturally related problems. One apparent limitation of the data is the limited representation of the UPAC files to the Asian American population, which may account for the distribution of sexual abuse reports being significantly lower for Asian Americans in this sample than the general population ( $4.9 \%$ vs. $12.3 \%$ ). Furthermore, reports of sexual abuse were found only among the Filipino and Vietnamese groups.

It is uncertain whether the occurrence of sexual abuse in Asian American populations is infrequent or whether the problem of sexual abuse is hidden within the community (Yap, 1986). It is also possible that the prevalence of sexual abuse in the Asian American population is low as well as underreported (Ima \& Hohm, 1991). Factors and motivators within Asian American culture that may contribute to possible underreporting of child sexual abuse will be addressed periodically throughout this article.

\section{Types of Sexual Abuse and Related Symptomatology}

Child sexual abuse in Asian Americans populations appears to differ on a number of dimensions from other ethnic communities. Such dimensions include the types of sexual abuse acts perpetrated, the symptoms manifested by the victims, relationship of the victim to the perpetrator, and the family's belief in the child's accusation. These factors were investigated by Rao et al. (1992). The researchers investigated 2007 charts at the Child and Adolescent Sexual Abuse Resource Center in San Francisco, California. Of these charts, only substantiated Asian American abuse cases were compared to a random sample of substantiated African American, European American, and Hispanic American abuse cases. Asian Americans were demographically different from the other ethnic groups in several ways. 
First, Asian Americans and Hispanic Americans were on average older and more likely to be immigrants than their African American and European American counterparts. Additionally, Asian Americans were more likely than other ethnic groups to be living in a shelter at the time of the evaluation and living with both parents. It should be noted that these demographic differences make it difficult to interpret differences between the ethnic groups. Nonetheless, this study by Rao et al. (1992) is one of the few studies that systematically examined the various dimensions of child sexual abuse among Asian Americans.

Rao et al. (1992) investigated the types of sexual abuse acts encountered by the victims according to ethnicity. They found that Asian Americans (36.4\%) and European Americans (36.4\%) were less likely to experience vaginal or anal intercourse as a form of sexual abuse than Hispanic Americans (50.0\%) and African Americans $(58.4 \%)$. The researchers also investigated psychiatric and behavioral symptomatology exhibited by child sexual abuse victims in their study. The most frequent symptoms reported by all victims, in descending order, were anxiety, dysphoria, anger, sleep disturbance, sexual acting out, suicidal ideation or attempts, somatic complaints, school problems, low self-esteem, running away, withdrawal, urinary disturbances (e.g., enuresis), clinging behavior, physical aggression toward others, and selfmutilation. Rao and colleagues (1992) found that Asian Americans were distinct from other ethnic groups in that they were more likely to express suicidal ideation or attempt suicide. Additionally, Asian Americans were distinct from the other ethnic groups in that they were least likely to display inappropriate sexual behavior and anger. It appears that Asian Americans are more likely to internalize their feelings rather than act out their feelings in response to child sexual abuse.

\section{Relationship to the Perpetrator}

To understand the dynamics pertaining to sexual abuse, it is also important to understand the relationship of the victim to the perpetrator. Rao et al. (1992) also investigated these factors. Approximately $60 \%$ of Asian American victims were abused by a male relative. They were the most likely ethnic group to be abused by a male relative, including the father, when compared to African American, European American, and Hispanic American abuse cases. Additionally, Asian American (14.7\%) and
Hispanic American (15.0\%) perpetrators were more likely to be living at home with the victim when they were evaluated by the clinic. These findings by Rao et al. (1992) are somewhat similar to those of Ima and Hohm (1991), who found that $50 \%$ of the sexual abuse perpetrators were fathers, while the other $50 \%$ of the perpetrators were someone other than the victim's parents.

\section{Caretaker Beliefs and Reactions}

Asian Americans are also distinct from other ethnic groups in terms of the primary caretaker's response to the abuse. In the study conducted by Rao et al. (1992), Asian American primary caretakers (e.g., mothers) were half as likely to report abuse to authorities as caretakers of other ethnic groups. Asian American caretakers (23.4\%) were also more likely to disbelieve the report of abuse than European American (6.7\%), African American (10.2\%), and Hispanic American (11.3\%) caretakers. Furthermore, Asian American caretakers were less likely than caretakers of other ethnic groups to complete the evaluation and treatment with the victim.

Wong (1987) of the Southeast Asian Child Sexual Assault Prevention Project (SEACAPP) in Renton, Washington, reported findings regarding belief systems pertaining to child sexual abuse. SEACAPP held focus-group discussions to explore what Southeast Asian refugees knew or believed about sexual assault. In general, Wong (1987) found a lack of awareness to the problem of child sexual abuse. She also discovered the presence of misconceptions surrounding the issue and a lack of awareness on how to deal with the problem of child sexual abuse. Wong (1987) further found that many of the participants did not believe that child sexual assault was a problem in their community, and many did not believe that family members would sexually assault a child. The community members also believed that assaults would be perpetrated only by a stranger. When asked how they would respond to sexual assault, most of the participants reported that they would keep the assault a secret within the family for fear of community rejection and blame. Furthermore, most of the participants were not aware of resources for child abuse victims other than requesting assistance from the police. Given the presence of misperceptions and the lack of awareness of resources for child sexual abuse victims, it is not surprising that the Asian American community is reporting lower rates of sexual abuse and is perhaps more likely to keep sexual abuse a secret. Given the absence of additional and more recent studies, it is unknown wheth- 
er the findings by Wong (1987) about awareness of and misconceptions about child sexual abuse in Asian American communities would be found in other or current samples.

The Rao et al. (1992) findings and the Wong (1987) impressions regarding the reporting of sexual abuse are consistent with the research by Hong and Hong (1991). Hong and Hong (1991) administered vignettes to 150 college students in California: 50 Chinese immigrants, 50 U.S.-born Hispanic Americans, and 50 U.S.-born European Americans. The 12 vignettes were developed from those used by Boehm (1964) and Giovannoni and Becerra (1979). All vignettes depicted parental conduct that may or may not be considered abusive or negligent (i.e., physical abuse, sexual abuse, parental neglect). The following is a vignette used by Hong and Hong: "Whenever the father is away from home, this mother will ask her 11year-old son to sleep in the same bed with her. She tells the boy that she feels lonely and does not want to sleep alone," (p. 465). The students were asked to select an intervention for each of the 12 cases (i.e., nothing needs to be done, family should be encouraged to seek professional help, child protective agency should be involved to investigate and help the family). The researchers found that the Asian American students were more reluctant to involve child protective agencies than Hispanic American and European American students. Asian American students were willing to involve the child protective agency only if they judged the parental conduct as highly abusive or negligent. Hong and Hong (1991) also found that Asian Americans had a higher tendency to recommend no action and were less likely to recommend professional assistance when compared to European Americans. This reflects the general conservatism Asian Americans may take in terms of reporting suspected abuse. It also suggests that Asian Americans have the tendency to recommend reporting only more severe forms of sexual abuse.

\section{Summary}

The overall empirical findings and impressions regarding child sexual abuse within the Asian American culture provide insight to some of the beliefs held by Asian Americans about the issue of child sexual abuse. They also support the possibility that sexual abuse is a hidden and underreported problem within the community. The lower prevalence of reported sexual abuse in Asian American communities may be associated with the misconceptions and denial of the problem of child sexual abuse within the community as well as the findings that victims are more likely to be victimized by a male relative who is living within the home and more likely to be disbelieved by their primary caretakers than members of other ethnic groups. These factors may be further compounded by the hesitance of Asian Americans to recommend professional help or notify child protective services in cases of abuse. Last, the finding that Asian American victims are more likely to internalize than externalize their feelings may further reduce motivation for the family to seek outside assistance.

\section{CULTURAL ISSUES AND VALUES}

Asian Americans and European Americans take a slightly different perspective in terms of world views. These differences are likely to play a role in attitudes toward the problem of sexual abuse. Additionally, these differences in cultural backgrounds may influence the prevalence, identification, and reporting of sexual abuse. It is for these reasons that cultural issues exemplifying harmony with the environment and attitudes toward sexuality are highlighted. The differences between Asian Americans and European Americans are based primarily on theoretical perspectives, cultural observations, and clinical experiences.

\section{Harmony with the Environment}

In Asian cultures, harmony with the environment is highly valued (Chung, 1992). Chung (1992) notes that this connection with nature is often expressed in Asian art, literature, architecture, and gardens. For example, in traditional Chinese paintings, the beauty and greatness of nature are highlighted. In contrast, Western art often emphasizes the representation of humans and the creations of humans. Human interactions in Asian American culture are also influenced by this concept of harmony (Chung, 1992). For example, the Asian American orientation toward collectivity, attitude towards family structure, and the values of conformity, middle-position virtue, shame, self-restraint, and suffering all reflect the Asian culture's appreciation of harmony. These specific cultural values are described in detail below.

Collectivity Versus Individuality. One of the primary differences between Asian American culture and European American culture is the way members view themselves 
in relation to others. Asian Americans are generally oriented toward the group whereas European Americans are generally oriented toward the individual (Chung, 1992; Chun-Hoon, 1971; Ho, 1990; Shon \& Ja, 1982; Sue \& Chin, 1993). As described by Chung (1992), Asian American identities are deeply rooted in the groups they belong to such as a family, business firm, school, or country. The needs of the group often take precedence over the needs of the individual. Alternatively, in European American culture, the individual and the needs of the individual are generally emphasized over those of the group. The identity of the individual is generally maintained in European American culture despite the groups with which the individual affiliates.

In both Asian American and European American cultures, the family is a fundamental group to which people belong. According to Shon and Ja (1982), European American families tend to emphasize the nuclear family. Asian American families, however, commonly include the nuclear family plus the extended family such as grandparents, aunts, and uncles. Furthermore, the concept of the Asian American family extends backward to all previous generations of the family line as well as forward to future generations (Ho, 1990; Shon \& Ja, 1982; Sue \& Chin, 1993).

Given this concept of family and collective orientation, the behaviors of an individual reflect not only on the individual but also on the nuclear family, extended family, and family ancestors, and they will influence future generations (Shon \& Ja, 1982). Problems within the family may not come to public attention to help preserve the reputation of and harmony within the family. Individual family members may be overlooked in order to maintain family unity, harmony, and continuity.

Disclosure of sexual abuse in any culture within the United States affects not only the abused child but the entire family. It is hypothesized that Asian American families, however, may be more hesitant to disclose sexual abuse to authorities than families of Western European descent given the Asian American definition of extended family, sense of collectivity, and emphasis on harmony. Furthermore, it is not uncommon for Asian children to recant allegation of child sexual abuse while "sacrificing their individual needs for the integrity of the family" (Okamura, Heras, \& Wong-Kerberg, 1995, p. 82). In Asian American culture, the problem of sexual abuse may more likely be dealt with within the family system.
This would explain the hypothesis the child sexual abuse is underreported in the Asian American community.

Family Structure. The traditional Asian American family may be compared to what is generally depicted as the traditional European American family. The roles and expectations of the Asian American family, however, are generally more strongly adhered to than today's European American family. In traditional Asian American families there are roles and positions of hierarchy that accompany the positions in the family (Cheng, 1997; Heras, 1992; Ho, 1990; Okamura et al., 1995; Uba, 1994). Members in the traditional Asian American family generally conform to these expected roles and their familial obligations. These roles and positions may function to preserve the harmony within the family. In general, elders have a higher status than those who are younger, and males are higher in the hierarchy than females (Ho, 1990; Uba, 1994). Generally, the father is the leader and authority of the family. He financially supports the family, makes the decisions, and is the disciplinarian (Lee, 1996; Shon \&Ja, 1982; Uba, 1994). The traditional mother is the nurturer of the family. She is the primary caregiver of the children, and she commonly performs a majority of the household tasks (Shon \&Ja, 1982; Song-Kim, 1992; Uba, 1994). The mother is the primary line of communication between the children and the father, and she frequently intercedes in behalf of the children (Shon \& Ja, 1982; Uba, 1994). However, she is typically ranked lower in the family hierarchy when compared to her husband, her father, her in-laws, and even at times, her son (Lee, 1996).

The role of children within the family is also structured. It is commonly mentioned in the literature that children are expected to respect the interests and wishes of their parents without question, sometimes sacrificing their feelings for the good of the family (Heras, 1992; Hong \& Hong, 1991; Thomas, 1992; Uba, 1994). Shon and Ja (1982) describe the oldest son as the most valued child in the Asian American family. He is the role model for the younger children as well as their authority. The oldest son is considered the head the family in the absence of the father. If the oldest son is unable to fulfill these obligations, the next oldest son will assume the position (Shon \& Ja, 1982). Daughters tend to lack authority within the family. In the traditional Asian American family, daughters are raised by their parents to marry and eventually become part of their hus- 
band's family (Dung, 1984; Shon \& Ja, 1982; Uba, 1994). Daughters are also expected to be passive (Sue \& Sue, 1999). This emphasis on close family ties and obligations is based on the concept of filial piety, which refers to unquestioning respect for parents, grandparents, and other elders (Ho, 1990). Filial piety is valued and generally expected from all members of the family.

As stated previously, Rao et al. (1992) found that approximately $60 \%$ of the Asian American sexual abuse victims were abused by a male relative. Similarly, Ima and Hohm (1991) found that 50\% of the sexual abuse perpetrators were fathers. Structural familial factors such as the absolute power of the father, the lack of status of daughters, and the expectation that children respect the interest and wishes of their parents may influence the reporting of sexual abuse to authorities. The power differential between the men and women in Asian American families also makes it more difficult for a woman to report sexual abuse, particularly when the perpetrator is a man within the family. Thus, the patriarchal aspects of Asian culture may place Asian American women at risk for sexual victimization (Hall, Windover \& Maramba, 1998).

Ima and Hohm (1991) hypothesize lower rates of reported abuse may be due to an actual lower incidence of abuse. The researchers speculate that the traditional hierarchical structure of the family creates a closer supervision of sexuality which may discourage sexual relations in the family. They provide the example that in Hmong culture there is pressure to discourage sibling incest by discouraging close physical and emotional relations. On the other hand, they speculate that the close monitoring of relations may also hide abuse. It is important to note that these speculations are hypotheses for consideration. In working with any client, it is important to understand the cultural background and norms. For example, Heras (1992) warns that therapists may be quick to judge the imbalance of power within the family as contributing to the sexual abuse rather than assessing the hierarchical structure as culturally appropriate.

Conformity, Inconspicuousness, and Middle-position Virtue. Abiding by rules and maneuvering within the boundaries of society are encouraged in both European American and Asian American cultures. In the Asian American culture, however, conformity is emphasized as a way of being in harmony with the societal groups. Harmony within society is also emphasized in Asian Ameri- can culture. Middle-position virtue is when the individual blends with others in society. When individuals adhere to the middle-position virtue, individuals become inconspicuous. The European American culture generally rewards individual creativity, assertiveness, and initiative, which differs from the Asian American cultural values of conformity, inconspicuousness, and middle-position virtue (Chun-Hoon, 1971; Sue \& Chin, 1983).

When child sexual abuse occurs, it jeopardizes the harmony of the nuclear family, extended family, community, and other groups involved. The perpetration of abuse does not conform to the rules of society, and allegations of sexual abuse are conspicuous and violate the middle-position virtue. Given this premise, it is possible that the actual incidence of abuse within the Asian American community is lower. However, it is also possible that these virtues serve to mask the reporting of sexual abuse to authorities in order to remain inconspicuous.

Shame. Child sexual abuse victims, especially in cases of incest, are generally raised in an environment which involves elements of secrecy, guilt, and shame (Damon, Card, \& Todd, 1992). Damon and colleagues (1992) also highlight that feelings of guilt and shame may be further complicated by children's tendency to blame themselves for the abuse due to egocentric thinking. These feelings become more complex when considering cultural values because Asian parents instill guilt and shame to control the behavior of family members (Sue, 1997). Therefore, feelings of guilt and shame may be an obstacle to the child disclosing sexual abuse experiences to others. Cultural dynamics may particularly discourage Asian Americans from disclosing what is perceived as shameful information (e.g., family violence) about their families (Lum, 1998). The social concept of shame in Asian American culture is frequently associated with the phrase "loss of face" in the literature (e.g., Shon \& Ja, 1982). The term loss of face is shame in the face of society. Shame and loss of face may be ways the culture enforces the virtues of conformity, inconspicuousness, and the middle-position virtue. Shame and loss of face attract attention to the individual as well as others associated with the individual. Again, in an interdependent, group-oriented society, when an individual shames him or herself, shame is also brought onto all groups with which that individual is associated. The consequences of shame and loss of face are severe in an interdependent society. When a person is 
shamed, there is the risk that family, community, and societal confidence and support will be withdrawn (Shon \& Ja, 1982). This may contribute to explanations regarding why shameful issues (e.g., sexual abuse) may be more likely kept within the family. These unspoken fears on both individual and community levels about revealing private family issues into the public may further contribute to keeping family violence invisible to save face and avoid public criticisms (Lum, 1998). In addition, Okamura and colleagues (1995) speculate that Asian Americans may move away from friends and relatives rather than confront the social stigma that may be attached to child sexual abuse.

Wong and Stone (1987) of the Southeast Asian Child Sexual Assault Prevention Project found through their contact with refugee service providers that a clean family reputation is highly valued. Sexual abuse in Asian American communities may not be reported due to the family's fear of rejection or blame by the community (Rao et al., 1992; Wong, 1987; Wong \& Stone, 1987). This is consistent with the impression of Amy Okamura, former program manager for the Union of Pan Asian Communities. According to Okamura, there is shame and loss of face when it is disclosed that a child was sexually abused (Thomas, 1992). She adds that if a child is placed in an outside agency, the shame continues in the community because the family is no longer intact. On the issue of domestic violence, Ho (1990) hypothesizes that the guilt and shame from public exposure may also inhibit future abuse.

Heras (1992) notes that Asian American clients may engage in face-saving behaviors that resemble denial or the nonacceptance of blame. She contrasts this to European American culture where acceptance of guilt and responsibility are signs of maturity and appropriate behavior. In traditional Asian American cultures, however, face saving may be an appropriate coping mechanism for preserving the integrity of the ego/self.

Self-control and Fatalism. Sexually abused children in both Western and Asian cultures may be hesitant to reveal information regarding sexual abuse to protect the unity and harmony of the family. Children of all cultures may opt to exercise self-control, self-restraint, and accept their fate to protect the offender. This may be especially true in cases of intrafamilial sexual abuse.

Self-control is a virtue that members of Asian American cultures are taught to respect. Ho (1976) notes that the rewards of self-control (e.g., achievement and success) bring pride not only to the individual, but also to the family. Legal involvement, unemployment, mental illness, and the expression of strong feelings are all considered signs of weakness and also reflect on the family in a shameful manner. In reference to domestic violence, Ho (1990) hypothesizes that self-restraint may function to restrain abuse in the home. On the other hand, she notes that restrained feelings may be acted out behaviorally. Similarly, Hall and colleagues (1998) speculate that self-control may serve as a protective factor in limiting sexually aggressive behaviors in Asian Americans.

Fatalism is the acceptance of one's situation. Ho (1976) describes fatalism as making the best of the situation without attempting to further control the environment. Fate may also be related to suffering and persevering. In Asian American cultures, the ability to suffer and persevere without complaint is beneficial in the development of a strong character (Ho, 1990). Ho (1990) further notes that the virtue of suffering and may prevent the victim of abuse from voicing the abuse to others. She adds that fatalism may also be a factor in the continuation of abuse by the victim suffering, persevering, and not taking action to change the situation. Lum (1998) also points out that this cultural value of accepting one's fate may inadvertently lead to an acceptance of family violence.

In general, traditional Asian Americans do not express their feelings openly. Within the marital subsystem, physical and verbal expressions of love are not commonly displayed in an open manner (Lee, 1996). Instead, the focus of the Asian American family is on the parent-child subsystem where parents generally expect respect and compliance from their children. Furthermore, elderly parents are commonly cared for by their adult children (Lee, 1996). Love in Asian American culture is more typically displayed through behaviors that benefit the family rather than verbal expressions or physical affection. Due to the use of nonverbal expressions of feelings in Asian cultures, it is not surprising that Asian Americans are less willing to discuss their mental health problems with an outsider.

\section{Attitudes Toward Sexuality}

Sexual chastity before marriage and faithfulness to a woman's husband after marriage are traditional Asian cultural values (Chan \& Leong, 1994). It appears that Asian Americans hold a more conservative view regarding sexuality than most European Americans. Chen and Yang (1986) compared the results of 67 Chinese American ad- 
olescents with the United States adolescent group-scale means of the Sexual Attitudes Scale. The researchers found that the Chinese American group was significantly more conservative in sexual attitudes and sexual behaviors than the United States adolescent comparison group.

Not only are Asian Americans more conservative in their sexual attitudes and behaviors, but they also appear to be more conservative in discussing the subject than European Americans. Sexuality is generally considered a taboo topic for discussion in Asian American culture (Bhugra \& Cordle, 1988; Chan, 1992; Chan \& Leong, 1994; Tsui, 1985), and discussion of this topic is extremely embarrassing and awkward for this population (Tsui, 1985). When discussions of sexuality do occur, it is usually limited to same-sex conversations (Okamura et al., 1995). Wong and Stone (1987) found a strong resistance in discussing topics related to sex in their focus group discussions through the Southeast Asian Child Sexual Assault Prevention Project. Wong and Stone (1987) identified the taboo of discussing sexually related issues as contributing to the vulnerability of sexual abuse in Southeast Asian refugee community. This lack of dialogue is consistent with Okamura's impression that many Asian American children are naive about sexual issues (Thomas, 1992).

These factors may also contribute to Wong's (1987) findings that misconceptions about sexual abuse exist within the community. An example of a misconception includes the belief that family members would not perpetrate the sexual abuse of a child. Wong and Stone (1987) also report that there is extensive denial that sexual assault exists as a potential problem in the Southeast Asian community. The authors note that the naiveté and taboo of discussing sexual-related issues may place children at risk of sexual abuse and may hinder the children's ability to inform adults about sexual assaults. Similarly, it may hinder the adult's ability to report sexual abuse to authorities.

This attitude contrasts to Western European society where the topic of sexually related issues is more open for discussion. The greater acceptance of discussing sexually related issues may also facilitate the dispersion of information about sexual abuse. Finkelhor (1984), in a survey of a primarily European American community, found that the community was relatively well informed about issues pertaining to sexual abuse. In 1981, Finkelhor conducted interviews with 521 parents in the Boston metropolitan area on a variety of issues related to sexual abuse (e.g., personal experiences with sexual abuse, perceptions on the seriousness of the problem). Almost all of the subjects were of European American descent (89\%). Finkelhor (1984) found that a majority of respondents had been exposed to the issue of sexual abuse the previous year (1980) through television $(90 \%)$ and the newspaper $(85 \%)$. He also found that European Americans were fairly accurate in estimating the prevalence of sexual abuse. Although parents underestimated the prevalence of sexual abuse, their estimates were not far from the prevalence of abuse reported in the literature.

Finkelhor (1984) also found misconceptions within the European American community. For example, he mentioned the term "sexual abuse" and asked subjects to identify what type of offender came to mind. Half of the parents responded stranger; $22 \%$ of the respondents mentioned a relative; and $28 \%$ of the respondents mentioned someone the child knew, but not a relative. This demonstrates the existence of the misconception that strangers are more likely to perpetrate sexual abuse. In actuality, sexual abuse perpetrated by strangers accounts for a relatively small proportion compared to perpetrators who are family members or acquaintances (Finkelhor, Hotaling, Lewis, \& Smith, 1990). This contrasts to the Asian American denial that sexual abuse may be perpetrated by a relative (Wong, 1987). Although misconceptions exist in the European American community, there appears to be some degree of awareness. Perhaps the greater acceptance of discussion about sexuality and sex-related issues does not eliminate but decreases misconceptions about sexual abuse.

\section{Treatment Issues in the Asian American Community}

Given that the sexual abuse treatment literature is sparse but growing, it is not surprising that there is even less literature addressing specific cultural issues in treating Asian American victims of child sexual abuse. Therefore, this section includes a broader discussion of the mental health system, recommendations for intervention, and preferred sources of support related to Asian Americans clients in general and child sexual abuse victims when applicable. Training and prevention programs focused on working with Asian American clients are also covered in this section.

\section{Utilization of and Satisfaction with the Mental Health System}

It is general consensus that Asian Americans underutilize the mental health system when compared with other ethnic groups (Crystal, 1989; Jew \& Brody, 1967; Kim, 1981; Leong, 1986; Loo, Tong, \& True, 1989; Root, 
1985; Suan \& Tyler, 1990; Zane \& Sue, 1991; Zhang, Snowden, \& Sue, 1998). Matsuoka, Breaux, and Ryujin (1997) statistically analyzed the 1986 National Institute of Mental Health survey data to obtain the overall national utilization rates of mental health services by Asian Americans. Matsuoka and colleagues discovered a differential pattern of usage, with Asian Americans being three times less likely than European Americans to use mental health services for all types of services across all types of facilities (e.g., inpatient, outpatient, residential care). However, when utilization of public mental health services were examined, Asian Americans were more likely to use individual therapy and medication management and were less likely to use crisis services compared to their European American counterparts (Hu, Snowden, Jerrell, \& Nguyen, 1991; Maynard, Ehreth, Cox, Peterson, \& McGann, 1997). Sue, Fujino, Hu, Takeuchi, and Zane (1991) examined information on outpatient clients that were submitted by mental health agencies to the Los Angeles County Department of Mental Health during a 5 -year period. Of the 230,441 clients, $43.0 \%$ were European Americans, 25.5\% were Latinos, 20.5\% were African Americans, 3.1\% were Asian Americans, and 2.9\% were other ethnic groups. The researchers compared these numbers to the county population, which consisted of 44.2\% European Americans, 33.7\% Latinos, 12.8\% African Americans, 8.7\% Asian Americans, and 0.6\% others. Thus, Asian Americans were underrepresented in mental health facilities, as were Latinos.

Sue and McKinney (1975) examined information on 13,450 patients (90.2\% European Americans and 0.7\% Asian Americans) that were submitted by mental health agencies to the Washington State Department of Social and Health Services. The researchers found that Asian Americans were more likely to terminate earlier in the therapeutic process than European Americans. Approximately $52 \%$ of Asian Americans terminated therapy after one session, compared to $30 \%$ of the European American clients. Not counting the initial intake interview, the researchers found that Asian American clients averaged 2.35 therapy sessions, whereas European American clients averaged 7.78 sessions. Thus, when Asian American clients seek mental health services, they are more likely to terminate therapy earlier than European American clients (O’Sullivan, Peterson, Cox, \& Kirkeby, 1989; Sue \& McKinney, 1975).

Dramatically different findings were discovered when culturally sensitive and ethnicity-specific mental health programs were examined (Sue et al., 1991; Takeuchi, Sue, \& Yeh, 1995). Takeuchi et al. (1995) examined mainstream and ethnicity-specific mental health programs in the Los Angeles area. For example, a Chinese therapist-Chinese client dyad was considered an ethnicity-specific match whereas a Chinese therapist-Japanese client was not regarded a match. They found that ethnicity-specific programs for Asian Americans were 6.6 times more likely to match client-therapist ethnicity than mainstream programs. In addition, Asian Americans in ethnicity-specific programs were more likely to return after the first session and stay for more treatment sessions compared to Asian Americans in mainstream programs (Takeuchi et al., 1995).

Sue and colleagues (1991) also examined the importance of culturally sensitive mental health programs. They found that for clients who do not speak English as the primary language, ethnic and language matches were important. In particular, Asian American clients whose primary language was not English who were matched either in ethnicity only, language only, or both were less likely to dropout of the therapeutic process and were more likely to attend more sessions than unmatched clients. Ethnicity match remained an important consideration when examining number of sessions in treatment among English-speaking Asian American clients. Sue and colleagues found that even though Asian Americans are not as likely to use mental health services, those who entered culturally sensitive treatment programs stayed for longer duration of services. Therefore, culturally sensitive and ethnicity-specific mental health programs appear to have a positive impact on Asian American clients.

In cases of child sexual abuse, Rao et al. (1992) found that Asian American caretakers were less likely to be involved in the initial intake process than European American, Hispanic American, and African American caretakers. Additionally, they found a trend that Asian American caretakers (39.4\%) were less likely than Hispanic American (45\%), European American (53.8\%), and African American (50.0\%) caretakers to complete the evaluation and treatment with the victim.

The studies conducted by Sue and McKinney (1975) and Rao et al. (1992) suggest that Asian American clients are at greater risk of premature termination of evaluation and treatment. Zane, Enomoto, and Chun (1994) provide possible reasons behind this phenomenon. The researchers conducted a treatment outcome study of 20 Asian American and 65 European American cli- 
ents in outpatient therapy in San Francisco, California. All Asian American clients were seen by Asian American therapists, whereas $68 \%$ of the European American clients were seen by Asian American therapists. Assessment measures included the Symptom Checklist (SCL90) by Derogatis, Lipman, and Covi (1973); the Brief Rating Scale, a shortened version of the Brief Psychiatric Rating Scale by Overall and Gorham (1962); and a Client Satisfaction Questionnaire. The researchers found that Asian American clients were less satisfied than European American clients with their treatment experiences in general after controlling for pretreatment levels of severity and socio-economic status. Asian American clients were less satisfied with their therapists, their access to service, progress in treatment, and the overall service received. Additionally, therapy was less effective for Asian Americans than European Americans in terms of alleviating distress (e.g., depression, hostility, anxiety) as rated by both clients and therapists.

The literature suggests that Asian Americans underutilize the mental health system, are at risk for premature termination, and are less satisfied with the system once they are involved. Given these findings there appear to be barriers that prevent Asian Americans from accessing and receiving satisfactory treatment from the mental health system. It is hypothesized that these barriers consist of cultural barriers as well as institutional barriers. Another possible reason for underutilization of the mental health system may be that Asian Americans tend to seek the assistance of other social support systems within the community in times of emotional distress. This may influence not only the apparent underutilization, but may also affect the lack of receptivity to the European American therapeutic system.

Cultural Barriers. Many of the Asian American traditional values mentioned previously may discourage Asian American families from seeking psychological support. For example, Chan and Leong (1994) note that the principles behind psychotherapy (e.g., individualism, self-determinism, and self-fulfillment) are in direct conflict with several traditional Asian cultural values (e.g., collectivism, interdependence, and loyalty to the family). Some additional factors that may inhibit Asian American clients from seeking psychological services are the stigma and shame attached with mental illness in the Asian American community (Crystal, 1989; Ng, 1997; Rao et al., 1992; Root, 1985; Sue \& Sue, 1987; Yap, 1986; Zane et al., 1994). Asian Americans tend to view mental illness as a personal weakness and lack of will power (Root, 1985). It has also been described as a punishment for past wrongs of the family and poor guidance and discipline from the family leader (Chan \& Leong, 1994). This feeling of weakness and perceived lack of will power conflicts with the valued Asian American values of self-control, suffering, and persevering in the face of adversity (C. K. Ho, 1990; M. K. Ho, 1976). Furthermore, due to the collective orientation of Asian Americans, the stigma and shame reflecting on an individual also reflects stigma and shame on all members of the family (Root, 1985; Sue \& Sue, 1987; Yap, 1986). These feelings are especially acute when problems are discussed with an outside party.

Another potential cultural barrier that may prevent Asian Americans from accessing and receiving satisfactory psychological services may be associated with the issues of awareness and trust in the American system. Ho (1990) asserts that Asian Americans are still considered foreign and different within America. Asian Americans are distinct because they appear physically different than European Americans regardless of assimilation, acculturation, and generation in the United States. Ho (1990) hypothesizes that Asian Americans are reluctant to report other Asian Americans to law officers or seek assistance from social services out of loyalty to the community. Furthermore, given possible confusion regarding the purposes of mental health services, there may be a fear of punishment, which may prevent Asian Americans from seeking mental health treatment for sexual abuse (Rao et al., 1992). Because mental health and psychotherapy are foreign concepts to many Asian Americans, this may lead to limited confidence in talking about problems (Sue \& Sue, 1999).

Institutional Barriers. In addition to possible cultural barriers, the literature suggests the existence of several pragmatic barriers that may prevent Asian Americans from seeking and accessing satisfactory psychological treatment. One of the most basic barriers that may prevent Asian Americans from accessing mental health services is the language barrier (Ho, 1990; Root, 1985). Often times immigrants and first-generation Asian American clients are unfamiliar with mental health resources in their community and are unable to access them (Ho, 1990; Rao et al., 1992; Wong, 1987). According to AbeKim and Takeuchi (1996), adequate access to mental health care systems for ethnic minorities have not been confirmed and thus cannot be assumed. Even if informa- 
tion regarding services is accessed, mental health agencies may not be able to serve this population due to the basic inability to communicate with the client.

Another pragmatic barrier that may prevent many Americans from seeking or obtaining mental health services is limited financial resources. Issues related to being underinsured or uninsured also need to be considered (Abe-Kim \& Takeuchi, 1996). Affordability may be a special concern in the Asian American community. Sue and Sue (1987) highlight statistics from the Office of Special Concerns (1 974) that indicate a higher percentage of poverty among Chinese Americans than the average American in the United States. Lee (1996) examined the U.S. Bureau of the Census 1990 statistics, population statistics analysis by the Asian American Health Forum (1990), and the limited descriptive data from researchers in the field of sociology and mental health. Lee found that Asian Americans as a group have the highest average family income in the United States. However, Southeast Asians are among the most financially disadvantaged with $66 \%$ of Laotians, $49 \%$ of Cambodians, and $34 \%$ of Vietnamese living below the poverty level. Lee (1996) also found that several Asian American groups (e.g., Chinese, Japanese, Asian Indian) have higher college graduation rates when compared to the overall United States population. However, the research also found that only $27 \%$ of Laotians and $38 \%$ of Cambodians are high school graduates. Based on these statistics, financial support may be necessary for Asian Americans seeking mental health services.

The barriers mentioned above (i.e., traditional values that may impede Asian Americans from seeking psychological support, awareness and trust in the American system, inability to communicate with mental health professionals, and limited financial resources) are related to another important consideration: the cultural sensitivity of mental health care settings. When child sexual abuse is reported, Asian American families are often further victimized by the child protection system (Okamura et al., 1995). For example, when allegations of child sexual abuse are made, children are often immediately removed from the home. Complications related to cross-cultural intervention (e.g., language barriers leading to miscommunications, cultural barriers leading to misunderstandings) may result in a prolonged delay in reunification of the child with his or her family or permanent placements (Okamura et al., 1995). Therefore, it is crucial that mental health professions are competent in working with
Asian American clients in a culturally sensitive manner. Furthermore, for Asian American clients whose primary language is not English, having a therapist matched in ethnicity and/or language was important in reducing premature termination, increasing number of sessions, and exhibiting greater improvement after treatment (Sue et al., 1991). Thus, culturally responsive services that include bilingual and bicultural ethnic mental health professionals are important. It is equally important for mental health professionals to be culturally competent. For example, mental health professionals should be nonjudgmental; have an awareness of different cultures, values, and beliefs; be flexible enough to change mental health practices to meet individual needs; be willing to learn about the client's views; and have an awareness of own attitudes and biases (Herrick \& Brown, 1998). In addition to cultural sensitivity, Murase (1992) found that community-based mental health service programs have been successful in Asian communities.

As mentioned before, Asian Americans are at special risk for premature termination of treatment (Sue \& McKinney, 1975). There is speculation that premature termination may be due to unfamiliarity with the process of psychotherapy, conflict over the direction of psychotherapy, or unacceptable cultural values therapists may use to measure healthy mental health functioning (Root, 1985). In working with new clients of any ethnicity, it is important to orient the client to the process of psychotherapy and work with the client in negotiating therapeutic expectations and goals. Given the underutilization of the mental health system by Asian Americans, this may be especially important when working with this population.

\section{Recommendations for Intervention When Working With Asian American Clients}

The general child sexual abuse treatment literature is sparse but growing. Different modalities (e.g., individual, group, family) for treating child sexual abuse victims have been conducted, but the current empirical evidence is limited. Furthermore, the current trend within clinical psychology is to depart from nondirective supportive therapy and shift toward the use of empirically validated treatment protocols (Ollendick, 1999; Weisz, Weiss, \& Donenberg, 1992). Despite this movement, there is a lack of standardized treatment programs for the child sexual abuse population. However, studies have shown preliminary support for using abuse-specific 
therapy to decrease related symptomatology (e.g., Berliner \& Saunders, 1996; Deblinger, Lippman, \& Steer, 1996). In one particular study, sexual abuse-specific cognitive behavioral therapy was found to be more effective in decreasing depressive symptomatology and associate with more clinical improvement than nondirective supportive therapy (Cohen \& Mannarino, 1998). Given that research on effective treatment of child sexual abuse has been emerging in the past decade, it is not surprising that the available research and data addressing specific cultural issues about treatment issues of child sexual abuse in Asian American community is minimal. With this caveat in mind, we review the general treatment literature and note specific discussion of its application and relevance for treating child sexual abuse in Asian American families. Possible specific recommendations are presented from the literature on treating child sexual abuse victims and their families.

Considerable concern is expressed in the literature regarding the lack of culturally responsive mental health treatment available to the Asian American population (Ho, 1990; Kim, 1985; Leong, 1986; Zane et al., 1994). It is for this reason that culturally specific recommendations are offered for working with Asian American clients. When Asian American clients present for therapy, they are likely to be reluctant, to rely on the clinician to be the authority figure or expert (e.g., expect the clinician to tell them what is wrong and solve their problems), to be unfamiliar with the treatment process, and to somaticize their symptoms (Chin, 1998). In working with cases of sexual abuse, demographic information as well as abuse-specific information is generally obtained during the assessment interview or from collateral resources. Additional cultural demographic information is helpful when working with Asian American clients to further facilitate case conceptualization and treatment planning. Such information may include country of origin, the generation of the client in America, how strongly the client adheres to the traditional customs, level of ethnic identity, level of acculturation, family experiences in the United States, socioeconomic status, and level of bilingualism (Chan, 1992; Ho, 1990; Kim, 1985; Lee, 1996; Thomas, 1992). Another cultural task the clinician may face in assessing sexual abuse in Asian American families is developing an understanding of what is considered culturally congruent and what is considered dysfunctional (Heras, 1992).

When initially interviewing the child who was sexually abused, it has been suggested that the child be inter- viewed with the trusted adult to whom he or she initially disclosed the abuse (Okamura et al., 1995). However, given the possibility of recanting the sexual abuse allegations to sacrifice individual needs for the integrity of the family, it is also suggested that the child not be interviewed in the presence of his or her family (Okamura et al., 1995). It is possible that the trusted adult is a family member. These conflicting suggestions further illustrate the complexity of issues that may arise when working with child sexual abuse victims in Asian American families. Nonetheless, the interviewer should also be sensitive to the child's feelings of isolation from the family and the potential fear of rejection. During the course of treatment, it is important to treat Asian clients with their families (Scully, Kuoch, \& Miller, 1995) to provide support for the client.

Ho (1990) provides recommendations for interventions when working with domestic violence in Asian American families. Her recommendations with domestic violence may be applicable in cases of child sexual abuse. Ho (1990) notes that the Asian American values of hierarchy and respect for authority may be used by the therapist and the legal system to work with the family. Asian Americans may be more likely to obtain treatment and follow through with treatment if it is recommended by a court of law. Asian American families may be more likely to adhere to court-ordered assessment and treatment given the Asian American respect for hierarchy and authority. Therefore, traditional Asian American families seldom challenge interventions of child abuse mandated by authority figures because such behavior would be perceived as disrespectful (Okamura et al., 1995).

Ho (1990) also suggests that community and family elders may be useful sources of support during the process of therapy. Translators may also be helpful; however, special attention may be necessary to ensure that the translators are translating as opposed to offering their own opinion or interpretation (Cheng, 1997; Ho, 1990). .Furthermore, treatment focused on trauma issues should not be conducted using other family members or nonprofessional translators (Scully et al., 1995). It is suggested that the availability of bilingual therapists may overcome the language barrier (Sue \& Chin, 1983; True, 1990). This may also reduce the chance of misinterpretation and the insertion of interpreter biases.

Sue and Sue's (1999) description of treatment strategies specific to Asian American clients may also be helpful in conceptualizing how to work with sexual abuse 
victims and their families. They summarized several other researchers' suggestions for clinicians as follows: (a) refrain from asking too many personal questions during the initial session; (b) assess current financial and social needs; (c) assess the problem from the client's perspective and view of the world; (d) focus on the specific problem as identified by the client; (e) take an active and directive role; (f) consider intergenerational conflicts; (g) view therapy as time limited, focused on resolution of problems, and deal with the present or immediate future; and (h) in the case of refugees, carefully assess the client's history related to information such as life in their home country, immigration experience, and expectations in the United States (Sue \& Sue, 1990). Even though these treatment strategies are broad, they provide a useful framework for therapist to consider.

Lee (1996) also provides specific recommendations for working with Asian American clients in family therapy. Due to the importance of family roles and structure within the Asian culture, these suggestions can be applied to working with child victims of sexual abuse and their families. Some of Lee's (1996) suggestions in the beginning phase include (a) appropriate self-disclosure from the clinician to develop trust and confidence; (b) form a social and cultural connection with the family or express interest and appreciation of the client's cultural background; (c) engage the family (e.g., using small talk) to develop rapport; (d) avoid direct confrontation, emotional disclosure, or a discussion of culturally taboo subjects such as sex or death; and (e) establish credibility because many Asian American clients believe the clinician is the authority who can tell them what is wrong and how to solve their problems. In addition, it is important to have the client identify family members and discuss who should be included in therapy because the definition of family in traditional Asian cultures often includes extended family members. Furthermore, Lee recommends a problem-focused, goal-oriented, and symptom-relieving approach in the beginning phase. More insight-oriented goals can be gradually introduced after the family is engaged in therapy (Lee, 1996). During the second, problem-solving phase, the following eight techniques are suggested: (a) focus on the problems the family presents, (b) apply a psychoeducational approach because education is highly valued in Asian cultures, (c) assume multiple helping roles (e.g., role of the counselor, teacher, advocate, interpreter), (d) indirectly solve problems because confrontation is viewed as disrespectful, (e) use re- framing technique by emphasizing the positive aspects of behavior, (f) capitalize on family strength and community support, (g) use intermediary functions such as a good family friend to link two uncommunicative family members, and (h) understand the family's communicative style. In the last, termination phase, Lee adds that clinicians should not expect an Asian client to verbalize anger or separation anxiety. Asian clients are more likely to view a good relationship with their clinician as a friendship that will continue after termination and to show their appreciation by inviting their clinician over for dinner or to bring a gift. Lee (1996) warns clinicians that these culturally appropriate gestures should not be interpreted as pathological.

Child sexual abuse victims in general are often times hesitant to share details of their experiences with others (Conte, 1990; Damon et al., 1992). Unless a child's safety is of concern, it is important that the therapist does not push the victim into talking about his or her abuse history. Given the taboo of discussing sexual behaviors and issues in Asian American culture, direct initial questions about the sexual abuse experience should be avoided. Damon and colleagues note that limitations in language and cognition in younger children may create difficulties for clinicians in the collection of information in verbal form. In working with sexual abuse victims of any culture, it is important that therapists notice nonverbal behavior during the course of therapy. Some therapists believe that the child's nonverbal behavior (e.g., change in affect, protective body language) when asked about specific aspects of the abuse may provide therapeutic clues to the clinician (Conte, 1990). The issue of recognizing nonverbal cues and behavior is especially important in working with Asian American clients due to the different communication style of this population from Western culture. Western culture tends to rely on verbal communication, whereas Asian American culture tends to emphasize non-verbal and indirect communication (Cheng, 1997; Chung, 1992). Asian Americans traditionally use indirect styles of communication and avoid confrontation (Lee, 1996). True (1990) encourages therapists to respect the client's reluctance to verbally or emotionally express themselves. Given these factors, it may be useful for the therapist to be more directive, active, structured, and goal directed in working with Asian American clients (Ho, 1976, 1984; True, 1990; Tsui \& Schultz, 1985). True also recommends the use of the educational approach when providing therapy to Asian American cli- 
ents which are consistent with the structured, goal directed form of therapy.

As in most therapeutic cases, it is helpful for the clinician to focus on the client and family strengths. Given the collective orientation in Asian American culture, it is particularly important for the clinician to assess strengths within the family and the family structure. Given the extensive trauma witnessed and experienced in Cambodia between 1979 and 1988, using genograms with Cambodian immigrants have been useful (Scully et al., 1995). Drawing a genogram of the family gives the client an opportunity to discuss the losses in their family, and family secrets (i.e., sexual assaults) may emerge. Scully and colleagues also emphasize the need to put the sexual abuse in the context of the trauma that occurred to the Cambodian culture and people before beginning treatment of sexual abuse victims. In her interview with Thomas (1992), Amy Okamura provided suggestions for working with Asian American abuse victims. She states that extended family members may be able to provide a similar family and cultural environment for the abused child. Okamura also states that acculturative processes may be necessary, such as orienting the family to America's child abuse laws. Focusing on the family learning about themselves, their bodies, and their feelings in a culturally sensitive and appropriate manner is also recommended. According to Okamura, the therapist may also function as a case manager by acting as a mediator between the family and the child protective system.

Families from all cultures may benefit from access to sexual abuse prevention programs in order to become better aware of the problem of sexual abuse, possibly prevent the occurrence of sexual abuse, and enhance awareness of interventions. It is equally important that prevention programs are culturally sensitive. Over the past decade, prevention programs targeting sexual abuse have been implemented on a widespread basis as awareness in the community has increased (Hazzard, 1990). Hazzard reports the existence of sexual abuse prevention programs and workshops within the United States aimed at educating children, parents, teachers, and police officers.

Within the Asian American community, Ho (1990) recommends culturally appropriate, awareness-raising discussion groups to explore relevant issues. Ima and Hohm (1991) speculate that child abuse cases in the Vietnamese community are handled by Vietnamese physicians. If this speculation is true, these physicians may be functioning as counselors. Herbalists, community elders and leaders, fortune tellers, and priests are often consulted in the Asian American community in times of need. Given the community's preference for these resources, these groups of community professional and leaders may benefit from education and discussion groups on child sexual abuse.

\section{Preferred Sources of Support}

Crystal (1989) notes that the underutilization of mental health services in the Asian American population may be attributed to alternative resources sought in times of emotional distress. Physical illness is a more acceptable form of weakness than mental illness. It is speculated in the literature that Asian Americans tend to somaticize their emotional feelings (Tseng, 1975; Westermeyer, Bouafuely, Neider, \& Callies, 1989). According to Ng (1997), somaticization empowers the somaticizer, makes sense of life problems, and allows the individual to present and communicate his or her problems without attaching the psychiatric stigma ( $\mathrm{Ng}, 1997)$. Given this tendency of somaticization, doctors rather than therapists are generally the first to be consulted by the Asian American family (Crystal, 1989; Root, 1985). Likewise, in Chinese culture a herbalist may be consulted for alleviation of emotional distress due to the belief that the distress is associated with a bodily imbalance of yin and yang (Crystal, 1989). Other community leaders such as priests or community leaders and elders may be sought in lieu of mental health practitioners in times of emotional distress (Crystal, 1989; Sue \& Chin, 1983; Yap, 1986). Given the preference for physicians, alternative healers, and community leaders, psychologists may serve an important consultative role with these individuals in treating child sexual abuse victims in Asian American families.

A study conducted by Zhang et al. (1998) describes a different perspective on somaticization contrary to common assumptions. The following three findings were described: (a) Asian Americans reported fewer somatic symptoms than European Americans; (b) the somatic complaints did not alter the difference between disclosure of mental distress; and (c) the number of somatic symptoms was positively associated with disclosing of mental health problems. These results suggest that somatic discomfort appears to motivate openness and is not ethnically specific. Furthermore, somatic complaints are not a defense against affective expression, but parallel emotional 
complaints as a mode of expression. In either the traditional (Ng, 1997; Tseng, 1975; Westermeyer, Bouafuely, Neider, \& Callies, 1989), or nontraditional (Zhang et al., 1998) assumptions of somaticization in Asian Americans, somatic complaints should be taken seriously, and psychological distress should be explored.

Given client cultural factors, institutional barriers, and the availability of more culturally accepted and possibly receptive support systems, it is speculated that Asian Americans seek mental health counseling as a last resort (Shon \& Ja, 1983; Sue \& Chin, 1983; Yap, 1986; Zane et al., 1994). Therefore, they may also present as more disturbed than other clients entering the mental health system (Shon \& Ja, 1983; Zane et al., 1994). Asian American resources within the community may be useful to the mental health practitioner in assessing the familial situation and providing cultural information. These resources in the community may also be valuable support systems to the family as they are dealing with the aftermath of childhood sexual abuse.

\section{Asian American Training and Prevention Programs}

There are two example programs in the literature focusing on Asian American populations. The first program was the National Asian American Psychology Training Center (NAAPTC) (Kim, 1981; Sue, 1981; Tanaka, 1981; Wong, 1981; Wong, Kim, Sue, \& Tanaka, 1981). In 1979, the National Institute of Mental Health funded a training grant proposal for the NAAPTC in San Francisco, California, to train clinical community psychology students in working with multiethnic populations (Sue, 1981; Tanaka, 1981 ;Wong, 1981). According to Sue (1981), the program's primary goal was to train competent clinical community psychologists using the scientist-practitioner model. These psychologists would then have an expertise in working with Asian American populations. The program focused on training psychologists by providing them with the knowledge of cultures, providing trainees with experiences with diverse cultural groups, and teaching trainees to use culturally appropriate intervention strategies (Kim, 1981). Asian American as well as supervisors of other ethnic groups were available to provide diverse perspectives (Kim, 1981). Again, the focus of the program was to develop fully-competent clinicians who also have specialized knowledge in working with Asian American populations. This program heightened the awareness of psychologists to the needs of Asian Americans and provided knowledge to others in the community on how to provide culturally responsive assessment and therapies to this population.

Another program that focused on the needs of Asian Americans was the Southeast Asian Child Sexual Assault Prevention Project (SEACAPP) (Wittet \& Wong, 1987; Wong, 1987; Wong \& Wittet, 1987). SEACAPP was developed in 1985 through King County Rape Relief, a private, nonprofit agency in Renton, Washington (Wong, 1987). The project focused on providing culturally sensitive information about sexual assault to the Southeast Asian refugee community. The information about the needs and perceptions of the community regarding the issue of sexual assault was collected through the implementation of focus-group discussions. Focus-group discussions were conducted separately for male and female adults. Likewise, separate focus-group discussions were held for male and female teenagers. The discussions were conducted in a language common to all members, and the facilitators were of the same ethnicity and gender as the members. Each of the discussions collected specific information about what Southeast Asian refugees knew or believed about sexual assault. The groups also discussed what types of guidance and advice Asian Americans provide to their children regarding personal safety, sexual conduct, and other related issues.

The information from the focus-group discussions was used to develop culturally sensitive booklets for parents and teenagers within the community (Wittet \& Wong, 1987; Wong, 1987; Wong \& Wittet, 1987). Each of the booklets define child sexual assault, provide guidelines for teaching children how to avoid assault, and present information on how to report sexual assault if it were to occur. Scenarios, educational information, large illustrations, and self-test quizzes are incorporated in the booklet. Furthermore, the parent booklet is translated into Chinese, Vietnamese, Lao, and Cambodian. In the back of each booklet are translations of terms (e.g., intercourse, incest, penis) in the aforementioned languages. Drafts of the booklets were piloted within the community and revisions were made. SEACAPP sent copies of the booklets to 500 agencies that serve Southeast Asians across the country to assist them in working with this community. The information was also presented in newspapers, conferences, community events, and health fairs. Finally, SEACAPP developed a curriculum to assist educators in providing sexual assault material to parents and children within the 
community (Wong, 1987). Videotapes and posters were also developed to heighten awareness and educate members of the community on the issue of sexual assault.

SEACAPP is unique in several respects. It collected useful information regarding the attitudes and needs of this population through focus-group discussions. The focus-group discussions were held in a culturally appropriate manner, thus taking into account Asian American values and sensitivities. Furthermore, this information was used to develop culturally sensitive educational materials. Perhaps the greatest asset of the program is that information was disseminated to other agencies, the general community, and the professional community so others may benefit from their resources and knowledge.

\section{CONCLUSION}

This article provided a broad overview and review of the literature on culturally relevant factors that may influence the prevalence, identification, and treatment of sexual abuse in Asian American families. Cultural factors are important for both therapists and researchers if the problem of sexual abuse is to be better understood and addressed within this community. Furthermore, these factors may assist in developing effective prevention programs and interventions for families in Asian American communities.

Perhaps the greatest limitation of this article is the limited empirical support for some of the positions in this paper. When empirical studies are present they tend to emphasize the study of one Asian American population (e.g., Chinese Americans, Southeastern refugees) and assumptions are cautiously extrapolated to other populations or subsets of populations within the Asian American community. At this time these limitations are realized but cannot be surmounted due to the infancy of Asian American psychology.

Zane and Sue (1991) outline the history of mental health research of Asian Americans. Serious mental health research focusing on Asian American populations essentially began in the late 1960s. During the mid1970s, the first mental health programs for Asian Americans were designed. In 1972 the First National Conference on Asian American Mental Health was held, and in 1978 the Asian American Psychological Association was established (Wong, 1981). Given the academic neglect and the only recently coordinated efforts of experts in this field, many programs were based on clinical impressions rather than on empirical research. Even today there is a need for increasing research devoted to Asian American studies in the field of psychology. The lack of valid assessment measures as well as treatment outcome studies for this population are evident. There is a call for more research on Asian American issues to gain insight into the types of services and culturally sensitive interventions that are the most effective (Chung, 1999; Chung \& Kamesh, 1999; Hall, 1999; Zane \& Sue, 1991). Further research is needed to guide interventions to increase the utilization of mental health services, the completion of treatment, and positive therapeutic outcomes. Zane et al. (1994) also call for more treatment outcome research to test and evaluate treatment models designed for the Asian American community. Special issues such as child sexual abuse within Asian American research are even less developed.

Again, it is important to remember that Asian Americans are a diverse and complex group. Many of the concepts discussed in this paper are generalizations to assist in the conceptualization of the problem of sexual abuse within this community. The theoretical concepts and conceptualizations in this article may be used to further our understanding for working with child sexual abuse victims in Asian American families. It is important to realize, however, that these conceptualizations are general guidelines and the intricacies of individual cases are just as important in case conceptualization. The continued independent development of the areas of sexual abuse and Asian American studies within the field of psychology is encouraging. As the two areas continue to develop independently as well as concurrently, the problem of sexual abuse in the Asian American community will continue to be better understood.

\section{NOTE}

Kristine T. Futa is now at the Permanente Medical Group, Union City, CA.

\section{ACKNOWLEDGMENT}

We express posthumous appreciation to Brian P. V. Sarata for his comments on earlier versions of the manuscript. Professor Sarata, a teacher and colleague, was dedicated to furthering acceptance and understanding of diversity.

\section{REFERENCES}

Abe-Kim, J. S., \& Takeuchi, D. T. (1996). Cultural competence and quality of care: Issues for mental health service delivery in managed care. Clinical Psychology: 
Science and Practice, 3, 273-295.

Bayatpour, M., Wells, R. D., \& Holford, S. (1992). Physical and sexual abuse as predictors of substance use and suicide among pregnant teenagers. Journal of Adolescent Health, 13, 128-132.

Bensley, L. S., Van Eenwyk, J., Spieker, S. J., \& Schoder, J. (1999). Self-reported abuse history and adolescent problem behaviors. I. Antisocial and suicidal behaviors. Journal of Adolescent Health, 24, 163-172.

Berliner, L., \& Saunders, B. (1996). Treating fear and anxiety in sexually abused children: Results of a controlled 2-year follow-up study. Child Maltreatment, 1, 292-309.

Beutler, L. E., Williams, R. E., \& Zetzer, H. A. (1994). Efficacy of treatment for victims of child sexual abuse. The Future of Children, 4, 156-175.

Bhugra, D., \& Cordle, C. (1988). A case control study of sexual dysfunction in Asian and non-Asian couples 1981-1985. Sexual and Marital Therapy, 3, 71-76.

Boehm, B. (1964). The community and the social agency define neglect. Child Welfare, 43, 453-464.

Browne, A., \& Finkelhor, D. (1986a). Impact of child sexual abuse: A review of the research. Psychological Bulletin, 99, 66-77.

Browne, A, \& Finkelhor, D. (1986b). Initial and long-term effects: A review of the research. In D. Finkelhor (Ed.), $A$ sourcebook on child sexual abuse (pp. 143-179). Beverly Hills, CA: Sage.

Chan, C. S. (1992). Cultural considerations in counseling Asian American lesbians and gay men. In S. H. Dworkin \& F. J. Gutierrez (Eds.), Counseling gay men and lesbians: Journey to the end of the rainbow (pp. 115-124). Alexandria, VA. American Association for Counseling and Development.

Chan, S., \& Leong, C. W. (1994). Chinese families in transition: Cultural conflicts and adjustment problems. journal of Social Distress and the Homeless, 3, 263-281.

Chen, C. L., \& Yang, D. C. Y. (1986). The self image of Chinese-American adolescents: A cross-cultural comparison. International Journal of Social Psychiatry, 32, 19-26.

Cheng, B. K. (1997). Cultural clash between providers of majority culture and patients of Chinese culture. Journal of Long-term Home Health Care, 16, 39-43.

Chin, J. L. (1998). Mental health services and treatment. In L. C. Lee \& N. W. S. Zane (Eds.), Handbook of Asian American psychology (pp. 485-504). Thousand Oaks, CA: Sage.

Chung, D. K. (1992). Asian cultural commonalities: A comparison with mainstream American culture. In S. M. Furuto, R. Biswas, D. K. Chung, K. Murase, \& F. RossSheriff (Eds.), Social work practice with Asian Americans (pp. 27-44). Newbury Park, CA: Sage.
Chung, R. G. (1999). Research issues in developing cultural competence. Asian American Psychologist, October, p. 5.

Chung, R. G., \& Ramesh, S. (1999). Diverse approaches to conducting research in Asian Americans. Asian American Psychologist, October, p. 6.

Chun-Hoon, L. (1971). Jade Snow Wong and the fate of Chinese-American identity. Amerasia Journal, 1, 53-63.

Cicchetti, D., \& Toth, S. L. (2000). Developmental processes in maltreated children. In D. J. Hansen (Ed.), Motivation and child maltreatment: The 46 ${ }^{\text {th }}$ Annual Nebraska Symposium on Motivation (pp. 85-160). Lincoln: University of Nebraska Press.

Cohen, J. A., \& Mannarino, A. P. (1998). Interventions for sexually abused children: Initial treatment outcome findings. Child Maltreatment, 3, 17-26.

Conte, J. R. (1990). Victims of child sexual abuse. In. R. T. Ammerman \& M. Hersen (Eds.), Treatment of family violence (pp. 50-76). New York: John Wiley \& Sons.

Crystal, D. (1989). Asian Americans and the myth of the model minority. Social casework, 70, 405-413.

Damon, L. L., Card, J. A, \& Todd, J. (1992). Incest in young children. In R. T. Ammerman \& M. Hersen (Eds.), Assessment of family violence: A clinical and legal sourcebook (pp. 148-172). New York: John Wiley \& Sons.

Deblinger, E., Lippman, J., \& Steer, R. (1996). Sexually abused children suffering posttraumatic stress symptoms: Initial treatment outcome findings. Child Maltreatment, 1, 310-321.

Derogatis, L., Lipman, R., \& Covi, L. (1973). SCL-90: An outpatient psychiatric rating scale (preliminary report). Psychopharmacology Bulletin, 9, 13-28.

Dung, T. N. (1984). Understanding Asian families: A Vietnamese perspective. Children Today, 10-12.

Einbender, A. J., \& Friedrich, W. N. (1989). Psychological functioning and behavior of sexually abused girls. Journal of Consulting and Clinical Psychology, 57, 155-157.

Faller, K. C. (1993). Child sexual abuse: Intervention and treatment issues. Washington, DC: U.S. Department of Health and Human Services.

Falshaw, L., Browne, K. D., \& Hollin, C. R. (1996). Victim to offender: A review. Aggression and Violent Behavior, 4, 389-404.

Finkelhor, D. (1984). Child sexual abuse: New theory and research. New York: The Free Press.

Finkelhor, D., \& Browne, A. (1985). The traumatic impact of sexual abuse: An update. Professional Psychology: Research and Practice, 21, 325-330.

Finkelhor, D., Hotaling, G., Lewis, I. A,, \& Smith, C. (1990). Sexual abuse in a national survey of adult men and women: Prevalence, characteristics, and risk factors. Child Abuse and Neglect, 14, 19-28, 
Friedrich, W. N., \& Reams, R. A. (1987). Course of psychological symptoms in sexually abused young children. Psychotherapy, 24, 160-170.

Giovannoni, J. M., \& Becerra, R. M. (1979). Defining child abuse. New York: The Free Press.

Hall, G. C. N. (1999). Asian American violence: An oxymoron? Asian American Psychologist, October, p. 9.

Hall, G. C. N., Windover, A. K., \& Maranlba, G. G. (1998). Sexual aggression among Asian Americans: Risk and protective factors. Cultural Diversity arid Mental Health, 4, 305-318.

Hanson, R. K. (1990). The psychological impact of sexual assault on women and children: A review. Annals of Sex Research, 3, 187-232.

Harrison, P. A., Hoffman, N. G., \& Edwall, G. E. (1989). Sexual abuse correlates: Similarities between male and female adolescents in chemical dependency treatment. Journal of Adolescent Research, 4, 382-399.

Hazzard, A. P. (1990). Prevention of child sexual abuse. In R. T. Ammerman \& M. Hersen (Eds.), Treatment of family violence (pp. 354-384). New York: John Wiley \& Sons.

Hecht, D. B., \& Hansen, D. J. (1999). Adolescent victims and intergenerational issues in sexual abuse. In V. B. Van Hasselt \& M. Hersen (Eds.), Handbook of psychological approaches with violent criminal offenders: Contemporary strategies and issues (pp. 303-328). New York: Plenum.

Hecht, D. B., \& Hansen, D. J. (in press). The environment of child maltreatment: Contextual factors and the development of psychopathology. Aggression and Violent Behavior. Heras, P. (1992). Cultural considerations in the assessment and treatment of child sexual abuse. Journal of Child Sexual Abuse, 1, 119-124.

Herrick, C. A., \& Brown, H. N. (1998). Underutilization of mental health services by Asian-Americans residing in the United States. Issues in Mental Health Nursing, 19, 225-240.

Ho, C. K. (1990). An analysis of domestic violence in Asian American communities: Multicultural approach to counseling. Women and Therapy, 9, 129-150.

Ho, M. K. (1976). Social work with Asian Americans. Social Casework, 57, 195-201. Ho, M. K. (1984). Social group work with Asian/Pacific-Americans. Social Work with Groups, 7, 49-61.

Hong, G. K., \& Hong, L. K. (1991). Comparative perspectives on child abuse and neglect: Chinese versus Hispanics and Whites. Child Welfare, 70, 463-475.

Hu, T. W., Snowden, L. R., Jerrell, J. M., \& Nguyen, T. D. (1991). Ethnic population in public mental health: Services choice and level of use. American Journal of Public Health, 81, 1429-1434.

Ima, K., \& Hohm, C. F. (1991). Child maltreatment among Asian and Pacific Islander refugees and immigrants: The
San Diego case. Journal of lnterpersonal Violence, 6 , $267-285$.

Jew, C. C., \& Brody, S. A. (1967). Mental illness among the Chinese: I. Hospitalization rates over the past century. Comprehensive Psychiatry, 8, 129-134.

Kim, S. C. (1981). The utilization of cultural variables in the training of clinical-community psychologists. Journal of Community Psychology 9, 298-300.

Lee, E. (1996). Asian American families: An overview. In M. McGoldrick, J. Giordano, \&J. K. Pearce (Eds.), Ethnicity and family therapy (2nd ed., pp. 227-248). New York: The Guilford Press.

Leong, F. T. L. (1986). Counseling and psychotherapy with Asian-Americans: Review of the literature. Journal of Counseling Psychology, 33, 196-206.

Livingston, R. (1987). Sexually and physically abused children. Journal of the American Academy of Child and Adolescent Psychiatry, 26, 413-415.

Loo, C., Tong, B., \& True, R. (1989). A bitter bean: Mental health status and attitudes in Chinatown. Journal of Community Psychology, 17, 283-296.

Lum, J. L. (1998). Family violence. In L. C. Lee \& N. W. S. Zane (Eds.), Handbook of Asian American psychology (pp. 505-525). Thousand Oaks, CA: Sage.

Matsuoka, J. K., Breaux, C., \& Ryujin, D. H. (1997). National utilization of mental health services by Asian Americans/ Pacific Islanders. Journal of Community Psychology, 25, 141-145.

Maynard, C., Ehreth, J., Cox, G. B., Peterson, P. D., \& McGann, M. E. (1997). Racial differences in the utilization of public mental health services in Washington State. Administration and Policy in Mental Health, 24, 411-424.

McClellan, J., Adams, J., Douglas, D., McCurry, C., \& Storck, M. (1995). Clinical characteristics related to severity of sexual abuse: A study of seriously mentally ill youth. Child Abuse and Neglect, 19, 1245-1254.

Mrazek, P. B., \& Mrazek, D. A. (1981). The effects of child sexual abuse: Methodological considerations. In P. B. Mrazek \& C. H. Kempe (Eds.), Sexually abused children and their families (pp. 236-245). New York: Pergamon.

Murase, K. (1992). Models of service delivery in Asian American communities. In S. M. Furuto, R. Biswas, D. K. Chung, K. Murase, \& F. Ross-Sheriff (Eds.), Social work practice with Asian Americans (pp. 101-120). Newbury Park, CA: Sage.

National Center on Child Abuse and Neglect. (1996). Third national incidence study of child abuse and neglect. Washington, DC: U.S. Department of Health and Human Services.

National Center on Child Abuse and Neglect. (1999). Child maltreatment 1997: Reports from the states to the National Child Abuse and Neglect data system. Washington, DC: 
U.S. Government Printing Office.

$\mathrm{Ng}, \mathrm{C} . \mathrm{H}$. (1997). The stigma of mental illness in Asian cultures. Australian and New Zealand Journal of Psychiatry, 31, 382-390.

Office of Special Concerns. (1974). A selected socioeconomic characteristics of ethnic minorities based on 1970 census, Vol. 2. Washington, DC: Department of Health, Education and Welfare.

Okamura, A, Heras, P., \& Wong-Kerberg, L. (1995). Asian, Pacific Island, and Filipino Americans and sexual child abuse. In L. A. Fontes (Ed.), Sexual abuse in nine North American cultures: Treatment and prevention (pp. 67-96). Thousand Oaks, CA: Sage.

Ollendick, T. H. (1999). Empirically supported treatments: Promises and pitfalls. The Clinical Psychologist, 52, 1-3.

O'Sullivan, M. J., Peterson, P. D., Cox, G. B., \& Kirkeby, J. (1989). Ethnic populations: Community mental health services ten years later. American Journal of Community Psychology, 17, 17-30.

Overall, J. E., \& Gorham, D. R. (1962). The Brief Psychiatric Rating Scale. Psychological Reports, 10, 799-812.

Rao, K., DiClemente, R.J., \& Ponton, L. E. (1992). Child sexual abuse of Asians compared with other populations. Journal of the American Academy of Child and Adolescent Psychiatry, 31, 880-886.

Root, M. P. (1985). Guidelines for facilitating therapy with Asian American clients. Psychotherapy, 22, 349-356.

Ryan, G. (1997). Consequences for the victim of sexual abuse. In G. D. Ryan \& S. L. Lane (Eds.), Juvenile sexual offending: Causes, consequences, and correction (pp. 157167). San Francisco: Jossey-Bass.

Sandhu, D. S. (1997). Psychocultural profiles of Asian and Pacific Islander Americans: Implications for counseling and psychotherapy. Journal of Multicultural Counseling and Development, 25, 7-22.

Scully, M., Kuoch, T., \& Miller, R. A. (1995). Cambodians and sexual child abuse. In L. A. Fontes (Ed.), Sexual abuse in nine North American cultures: Treatment and prevention (pp. 97-127). Thousand Oaks, CA: Sage.

Shon, S. P., \& Ja, D. Y. (1982). Asian families. In M. McGoldrick, J. Pearce, \&J. Giordano (Eds.), Ethnicity and family therapy (pp. 208-229). New York: Guilford.

Singer, M. I., Song, L., \& Ochberg, B. (1994). Sexual victimization and substance abuse in psychiatrically hospitalized adolescents. Social Work Research, 18, 97-103.

Song-Kim, Y. I. (1992). Battered Korean women in urban United States. In S. M. Furuto, R. Biswas, D. K. Chung, K. Murase, \& F. Ross-Sheriff (Eds.), Social work practice with Asian Americans (pp. 213-226). Newbury Park, CA: Sage.
Suan, L. V., \& Tyler, J. D. (1990). Mental health values and preference for mental health resources of JapaneseAmerican and Caucasian-American students. Professional Psychology: Research and Practice, 21, 291-296.

Sue, $D$. (1997). The interplay of sociocultural factors on the psychological development of Asian in America. In D. R. Atkinson, G. Morten, \& D. W. Sue (Eds.), Counseling American minorities: A cross-cultural perspective (5th ed., pp. 205-213). Boston: McGraw-Hill.

Sue, D. W., \& Sue, D. (1987). Asian-Americans and Pacific Islanders. In P. Pedersen (Ed.), Handbook of cross-cultural counseling and therapy (pp. 141-155). New York: Praeger.

Sue, D. W., \& Sue, D. (1999). Counseling the culturally different: Theory and practice (3rd ed., pp. 255-271). New York: John Wiley.

Sue, S. (1981). Programmatic issues in the training of Asian-American psychologists. Journal of Community Psychology, 9, 293-297.

Sue, S., \& Chin, R. (1983). The mental health of ChineseAmerican children: Stressors and resources. In G. J. Powell, J. Yamamoto, A. Romero, \& A. Morales (Eds.), The psychosocial development of minority group children (pp. 385-397). New York: Bruner-Mazel.

Sue, S., Fujino, D.C., Hu, L., Takeuchi, D. T., \& Zane, N. W. S. (1991). Community mental health services for ethnic minority groups: A test of the cultural responsiveness hypothesis. Journal of Constructing and Clinical Psychology, 59, 533-540.

Sue, S., \& McInney, H. (1975). Asian Americans in the community mental health care system. American Journal of Orthopsychiatry, 45, 111-118.

Takeuchi, D. T., Sue, S., \& Yeh, M. (1995). Return rates and outcomes from ethnicity-specific mental health programs in Los Angeles. American Journal of Public Health, 85, 638-643.

Tanaka, M. (1981). Products of clinical-community-based training: National Asian American Psychology Training Center. Journal of Community Psychology, 9, 301-305.

Thomas, J. (1992). An interview with Amy Okamura. The Advisor: American Professional Society on the Abuse of Children, 8, 16-18.

Tong, L., Oates, K., \& McDowell, M. (1987). Personality development following sexual abuse. Child Abuse and Neglect, 11, 371-383.

True, R. H. (1990). Psychotherapeutic issues with Asian American women. Sex Roles, 22, 477-486.

Tseng, W. (1975). The nature of somatic complaints among psychiatric patients: The Chinese case. Comprehensive Psychiatry, 16, 237-245.

Tsui, A. M. (1985). Psychotherapeutic considerations in sexual counseling for Asian immigrants. Psychotherapy, 22, 357-362. 
Tsui, P., \& Schultz, G. L. (1985). Failure of rapport: Why psychotherapeutic engagement fails in the treatment of Asian clients. American Journal of Orthopsychiatry, 55, 561-569.

Uba, L. (1994). Asian Americans: Personality patterns, identity, and mental health. New York: Guilford.

U.S. Bureau of the Census. (1992). 1990 Census of population: General population characteristics. Washington, DC: U.S. Government Printing Office.

U.S. Bureau of the Census. (1994). County and city data book: 1994. Washington, DC: U.S. Government Printing Office.

Weisz, J. R., Weiss, B., \& Donenberg, G. K. (1992). The lab versus the clinic: Effects of child and adolescent psychotherapy. American Psychologist, 47, 1578-1585.

Wells, R. D., McCann, J., Adams, J., Voris, J., \& Ensign, J. (1995). Emotional, behavioral, and physical symptoms reported by parents of sexually abused, nonabused, and allegedly abused prepubescent females. Child Abuse and Neglect, 19, 155-163.

Westermeyer, J., Bouafuely, J., Neider, J., \& Callies, A. (1989). Somatization among refugees: An epidemiologic study. Psychosomatics, 30, 33-43.

Wittet, S., \& Wong, D. (1987). Helping your child be safe. Renton, WA: King County Rape Relief.

Wolfe, V. V., \& Wolfe, D. A. (1988). The sexually abused child. In E. J. Mash \& L. G. Terdal (Eds.), Behavioral assessment of childhood disorders (2nd ed., pp. 670-714). New York: Guilford.

Wong, D. (1987). Preventing child sexual assault among Southeast Asian refugee families. Child Today, 16, 18-22.
Wong, D., \& Stone, M. E. (1987). Southeast Asian child sexual abuse prevention project. Unpublished manuscript.

Wong, D., \& Wittet, S. (1987). Be aware. Be safe. Renton, WA: King County Rape Relief.

Wong, H. Z. (1981). Contextual factors for the development of the National Asian American Psychology Training Center. Journal of Community Psychology, 9, 289-292.

Wong, H. Z., Kim, S. C., Sue, S., \& Tanaka, M. (1981). The training of ethnic minority clinical-community psychologists: The case of Asian-Americans. Journal of Community Psychology, 9, 287-288.

Wozencraft, T., Wagner, W., \& Pelligrin, A. (1991). Depression and suicidal ideation in sexually abused children. Child Abuse and Neglect, 15, 505-511.

Yap, J. G. (1986).Philippine ethnoculture and human sexuality. Journal of Social Work and Human Sexuality, 4, 121-134.

Zane, N., Enomoto, K., \& Chun, C. (1994). Treatment outcomes of Asian- and White-American clients in outpatient therapy. Journal of Community Psychology, 22, 177-191.

Zane, N., \& Sue, S. (1991).Culturally responsive mental health services for Asian Americans: Treatment and training issues. In H. F. Meyers, P. Wohlford, L. P. Guzman, \& R. J. Echemendia (Eds.), Ethnic minority perspectives on clinical training and services in psychology (pp. 49-58). Washington, DC: American Psychological Association.

Zhang, A. Y., Snowden, L. R., \& Sue, S. (1998). Difference between Asian and White Americans' help seeking and utilization patterns in the Los Angeles area. Journal of Community Psychology, 26, 317-326. 